OPEN ACCESS

Edited by:

Michael Gänzle

University of Alberta, Canada

Reviewed by:

Sergio I. Martinez-Monteagudo,

South Dakota State University,

United States

Catherine Maeve Burgess,

Teagasc, The Irish Agriculture and

Food Development Authority, Ireland

*Correspondence:

Xiaojun Liao

liaoxjun@hotmail.com

Specialty section:

This article was submitted to

Food Microbiology,

a section of the journal

Frontiers in Microbiology

Received: 01 September 2017 Accepted: 07 December 2017 Published: 18 December 2017

Citation:

Bi X, Wang Y, Hu X and Liao X (2017) ITRAQ-Based Proteomic Analysis of

Sublethally Injured Escherichia coli 0157:H7 Cells Induced by High

Pressure Carbon Dioxide.

Front. Microbiol. 8:2544.

doi: 10.3389/fmich.2017.02544

\section{iTRAQ-Based Proteomic Analysis of Sublethally Injured Escherichia coli 0157:H7 Cells Induced by High Pressure Carbon Dioxide}

\author{
Xiufang $\mathrm{Bi}^{1,2,3}$, Yongtao Wang ${ }^{1,2}$, Xiaosong $\mathrm{Hu}^{1,2}$ and Xiaojun Liao ${ }^{1,2 *}$ \\ ${ }^{1}$ Beijing Advanced Innovation Center for Food Nutrition and Human Health, College of Food Science and Nutritional \\ Engineering, China Agricultural University, Beijing, China, ${ }^{2}$ Key Lab of Fruit and Vegetable Processing, Ministry of Agriculture, \\ Beijing, China, ${ }^{3}$ Sichuan Key Laboratory of Food Bio-technology, College of Food and Bioengineering, Xihua University, \\ Chengdu, China
}

High pressure carbon dioxide (HPCD) could cause sublethally injured cells (SICs), which may cause food poisoning and spoilage during food storage and limit its application. Therefore, the formation of SICs of Escherichia coli O157:H7 was investigated by isobaric tag for relative and absolute quantification (iTRAQ) proteomic methods in this study for better controlling the SICs induced by HPCD. A total of 2,446 proteins was identified by iTRAQ, of which 93 and 29 were significantly differentially expressed in the SICs compared with live control cells $\left(\mathrm{CK}_{\mathrm{L}}\right)$ and dead control cells $\left(\mathrm{CK}_{\mathrm{D}}\right)$, respectively. Among the 93 differentially expressed proteins (DEP) in the SICs compared with $\mathrm{CK}_{\mathrm{L}}, 65$ proteins showed down-regulation and 28 showed up-regulation. According to the comprehensive proteome coverage analysis, the SICs survived under HPCD by reducing carbohydrate decomposing, lipid transport and metabolism, amino acid transport and metabolism, transcription and translation, DNA replication and repair. Besides, the SICs showed stress response, DNA damage response and an increased carbohydrate transport, peptidoglycan synthesis and disulfide bond formation to HPCD. Among the 29 DEP in the SICs compared with $\mathrm{CK}_{\mathrm{D}}, 12$ proteins showed down-regulation and 17 showed up-regulation. According to the comprehensive proteome coverage analysis, the SICs survived under HPCD by accumulation of cell protective agents like carbohydrates and amino acids, and decreasing transcription and translation activities. Results showed that the formation of the SICs with low metabolic activity and high survival ability was a survival strategy for E. coli O157:H7 against HPCD.

Keywords: Escherichia coli 0157:H7, sublethal injury, high pressure carbon dioxide, proteome, stress response

\section{INTRODUCTION}

Escherichia coli O157:H7 is a type of enterohemorrhagic, Shiga toxin producing E. coli (EHEC) first indentified in 1982 (Riley et al., 1983). This pathogen could cause foodborne outbreaks worldwide, e.g., foodborne outbreaks, including 4,928 illnesses, 1,272 hospitalizations, and 33 deaths, were identified to be caused by E. coli O157:H7 in the United States from 2003 to 2012 (Heiman et al., 2015). The majority of outbreaks caused by E. coli O157:H7 have been linked to the consumption of 
contaminated foods such as beef, leafy vegetables, and drinking water (Marder et al., 2014; Heiman et al., 2015). It has been reported the infective dose of E. coli O157:H7 was low and may be as few as 10 cells (Phillips, 1999). In the efforts to improve food safety by inactivating E. coli O157:H7 cells, thermal pasteurization techniques are widely used. However, nutritive compounds, color, texture, taste and aroma could be destroyed, especially for fruits and vegetables products. Therefore, nonthermal pasteurization techniques, which aim to achieve similar microbial with minimal impact on food quality, have gained much attention (Garcia-Gonzalez et al., 2007).

High pressure carbon dioxide (HPCD), a novel non-thermal technology, can effectively inactivate $E$. coli in carrot juice (Bi et al., 2014) and apple juice (Liao et al., 2007). The bactericidal effects, kinetics and mechanisms of HPCD-induced inactivation have been mostly investigated (Liao et al., 2007, 2011). In recent years, researchers found that some sublethally injured cells (SICs) may survive after HPCD despite having sustained membrane damage (Yuk and Geveke, 2011; Bi et al., 2015). Bi et al. (2015) found HPCD caused sublethal injury to E. coli O157:H7 cells, which could not recover in the selective medium, leading to an overestimation of lethality of HPCD processing. However, the SICs could recover during storage under favorable conditions, posing a potential health risk for HPCD-treated products (Garcia-Gonzalez et al., 2007). In order to understand and control the SICs induced by HPCD, it is very important to understand how SICs were formed during HPCD processing.

Until now, studies on the SICs caused by non-thermal pasteurization techniques are mainly focused on its induction, recovery and physiological properties (Sokołowska et al., 2014; Bi et al., 2015; Wang et al., 2015; Li et al., 2017). Only a few studies were carried out on molecular characteristics of the SICs which could help reveal its formation mechanisms (Ulmer et al., 2002; Molina-Höppner et al., 2004; Kilimann et al., 2006; Zhao et al., 2014a,b). However, these studies investigated the relationship between formation of the SICs and a few membrane-related enzymes (e.g., $\mathrm{Ca}^{2+}$-ATPase, LmrP, HorA), which can partly reveal the formation mechanisms of the SICs induced by high pressure and pulse electric fields (PEF).

Quantitative proteomics, firstly proposed by Wilkins and Williams in 1994, has been used in the mechanistic study of cell responses to stress (Jin et al., 2017). Using two-dimensional electrophoresis (2-DE) proteomic analysis, Rivas et al. (2013) found the protein profile of the SICs of E. coli DH5 $\alpha$ induced by PEF was significantly different from the untreated cells, and the differentially expressed proteins (DEP) were mainly some structural and metabolic proteins (ompA, gmhA, ClpA, RS6, Dut, FtnA, TufB, ftsH, putA, atpA, and sdhA). By analyzing the function of these DEP, a better understanding of the formation mechanisms of the SICs induced by PEF was achieved (Rivas et al., 2013). To our knowledge, no study has been carried out on the proteomic profiles of the SICs induced by HPCD so far. The isobaric tags for relative and absolute quantification (iTRAQ) combined with multidimensional liquid chromatography and tandem MS analysis is one of most powerful methodologies in quantitative proteomics (Yang et al., 2016). In addition, it allows for simultaneous relative quantification of up to eight samples within a single run, which could ensure the confidence of comparison. Therefore, iTRAQ-based quantitative proteomics analysis was applied to investigate the proteomic profiles in the SICs of E. coli O157:H7 induced by HPCD in this study.

\section{MATERIALS AND METHODS}

\section{Chemicals}

Tetraethylammonium bromide (TEAB) and iTRAQ reagent were purchased from Applied Biosystems (Milan, Italy). Tryptic soy broth (TSB) was purchased from Beijing Aoboxing Biological Technology Co. Ltd (Beijing, China). Bradford protein assay kit was purchased from Thermo Fisher Scientific (Massachusetts, USA). Trypsin Gold was purchased from Promega Corporation (Wisconsin, USA). Acetonitrile (ACN) and formic acid (FA) of high-performance liquid chromatography (HPLC) grade were purchased from Honeywell Burdick \& Jackson (SK Chemicals, Seoul, Korea). Other chemicals were obtained from Beijing Chemicals Co. (Beijing, China).

\section{Bacterial Strain and Induction of the SICs by HPCD Treatment}

E. coli O157:H7 NCTC 12900 was obtained from the National Culture Type Collection (Colindale, London, United Kingdom). E. coli cells grown in TSB at $37^{\circ} \mathrm{C}$ for $3 \mathrm{~h}$ (intermediate exponential phase) were centrifuged at $7669.4 \mathrm{~g}$ for $10 \mathrm{~min}$ at $4^{\circ} \mathrm{C}$ (CF16RXII, HITACHI, Japan). The harvested cells were then washed and resuspended in sterile phosphate-buffered saline (PBS: $10 \mathrm{mM}$ potassium phosphate buffer, $8.4 \mathrm{~g} / \mathrm{L} \mathrm{NaCl}, \mathrm{pH} 7.00$ ) (Beijing Chemical Works, Beijing, China). In accordance with the procedure described by Bi et al. (2015), sublethally injured E. coli cells $\left(\approx 10^{7} \mathrm{CFU} / \mathrm{mL}\right)$ were generated by $\mathrm{HPCD}$ at $5 \mathrm{MPa}$ and $37^{\circ} \mathrm{C}$ for $15 \mathrm{~min}$. HPCD treatment was performed with a batch HPCD system (Liao et al., 2007). Twenty milliliter of E. coli cells was transferred to a $50 \mathrm{~mL}$ sterile glass tube and the tube was covered with a plastic film (Beijing Lanyi chemical products Co. Ltd., Beijing, China) with a $0.22 \mu \mathrm{m}$ membrane filter in the center for aeration and preventing microbial contamination. As the pressure vessel of the HPCD system reached the experimental temperature, the sample tubes were placed in the pressure vessel. The vessel was pressurized by the plunger pump to required pressure and held for the required treatment time. Then, the depressurization was performed by opening the pressure relief valve of $\mathrm{CO}_{2}$. The compression time was in the range of 40$60 \mathrm{~s}$ and the depressurization time was 30-60 s. After HPCD treatment, the percentages of intact cells, dead cells, and SICs in suspension were $32.7,21.4$, and $45.9 \%$, respectively (Bi et al., 2015). Therefore, both intact cells and dead cells were used as controls in the following study. Untreated E. coli cells at intermediate exponential phase served as control of intact live cells $\left(\mathrm{CK}_{\mathrm{L}}, \approx 10^{8} \mathrm{CFU} / \mathrm{mL}\right)$, and cells treated by $\mathrm{HPCD}$ at $5 \mathrm{MPa}$ and $37^{\circ} \mathrm{C}$ for $40 \mathrm{~min}$ was used as control of dead cells $\left(\mathrm{CK}_{\mathrm{D}}, \approx 10^{7}\right.$ $\mathrm{CFU} / \mathrm{mL})$.

\section{Protein Preparation}

Ten replicates of untreated and HPCD-treated E. coli cells were collected and mixed evenly, separately. Then the proteins 
were extracted according to Liao et al. (2011) with some modifications. The cells were washed with sterile phosphate buffered saline (PBS, $\mathrm{pH}$ 7.0), and ground into powder in liquid nitrogen, extracted with Lysis buffer (7 M Urea, $2 \mathrm{M}$ Thiourea, 4\% CHAPS, $40 \mathrm{mM}$ Tris- $\mathrm{HCl}, \mathrm{pH}$ 8.5) containing $1 \mathrm{mM}$ phenylmethylsulfonyl fluoride (PMSF) and $2 \mathrm{mM}$ EDTA (final concentration). After $5 \mathrm{~min}, 10 \mathrm{mM}$ dithiothreitol (DTT, final concentration) was added to the samples. The suspension was sonicated at $200 \mathrm{~W}$ for $15 \mathrm{~min}$ (JY92-II, Ningbo Xinzhi biological Polytron Technologies Inc., Ningbo, China) and then centrifuged at $25,000 \mathrm{~g}$ and $4^{\circ} \mathrm{C}$ for $20 \mathrm{~min}$ (CF16RXII, Hitachi, Ltd., Tokyo, Janpan). The supernatant was mixed well with $5 \times$ volume of chilled acetone containing $10 \%(\mathrm{v} / \mathrm{v})$ trichloroacetic acid (TCA) and incubated at $-20^{\circ} \mathrm{C}$ for $2 \mathrm{~h}$. After centrifugation at $16,000 \mathrm{~g}$ and $4^{\circ} \mathrm{C}$ for $20 \mathrm{~min}$, the supernatant was discarded. The precipitate was dissolved in Lysis buffer ( $7 \mathrm{M}$ urea, $2 \mathrm{M}$ thiourea, 4\% NP40, $20 \mathrm{mM}$ Tris- $\mathrm{HCl}, \mathrm{pH}$ 8.0-8.5) containing $1 \mathrm{mM}$ PMSF and $2 \mathrm{mM}$ EDTA (final concentration). After $5 \mathrm{~min}, 10 \mathrm{mM}$ DTT (final concentration) was added to the samples. The suspension was sonicated at $200 \mathrm{~W}$ for $15 \mathrm{~min}$ and centrifuged at $25,000 \mathrm{~g}$ and $4^{\circ} \mathrm{C}$ for $20 \mathrm{~min}$. The supernatant was collected.

To reduce disulfide bonds in proteins of the supernatant, $10 \mathrm{mM}$ DTT (final concentration) was added and incubated at $56^{\circ} \mathrm{C}$ for $1 \mathrm{~h}$. Subsequently, $55 \mathrm{mM}$ iodoacetamide (IAM, final concentration) was added to block the cysteines, incubated for $45 \mathrm{~min}$ in the darkroom. The supernatant was mixed well with $55 \times$ volume of chilled acetone for $2 \mathrm{~h}$ at $-20^{\circ} \mathrm{C}$ to precipitate proteins. After centrifugation at $25,000 \mathrm{~g}$ and $4^{\circ} \mathrm{C}$ for $20 \mathrm{~min}$, the supernatant was discarded, and the pellet was air-dried for $5 \mathrm{~min}$, dissolved in $200 \mu \mathrm{L} 0.5 \mathrm{M}$ TEAB and sonicated at $200 \mathrm{~W}$ for $15 \mathrm{~min}$. Finally, samples were centrifuged at $25,000 \mathrm{~g}$ and $4{ }^{\circ} \mathrm{C}$ for $20 \mathrm{~min}$. The supernatant was collected and the proteins were quantified, using Bradford protein assay kit. The proteins in the supernatant were kept at $-80^{\circ} \mathrm{C}$ for further analysis.

\section{iTRAQ Labeling and Strong Cation Exchange (SCX) Chromatography}

According to the iTRAQ protocol provided by Applied Biosystems (Milan, Italy), total protein $(100 \mu \mathrm{g})$ was taken out of each sample solution and then the protein was digested with Trypsin Gold with the ratio of protein: trypsin $=30: 1$ at $37^{\circ} \mathrm{C}$ for $16 \mathrm{~h}$. After trypsin digestion, peptides were dried by vacuum centrifugation. Peptides were reconstituted in $0.5 \mathrm{M}$ TEAB and processed according to the manufacture's protocol for 8-plex iTRAQ reagent. Briefly, one unit of iTRAQ reagent was thawed and reconstituted in $24 \mu \mathrm{L}$ isopropanol. Samples were labeled with the iTRAQ tags as follow: sample SICs (115 tag), sample $\mathrm{CK}_{\mathrm{L}}$ (113 tag), sample $\mathrm{CK}_{\mathrm{D}}$ (119 tag). Samples were tested in duplicates in a single run. The peptides were labeled with the isobaric tags, incubated at room temperature for $2 \mathrm{~h}$. The labeled peptide mixtures were then pooled and dried by vacuum centrifugation.

SCX chromatography was performed as described by Pandhal et al. (2011) with a LC-20AB HPLC Pump system (Shimadzu, Kyoto, Japan). The iTRAQ labeled peptide mixtures were reconstituted with $4 \mathrm{~mL}$ buffer $\mathrm{A}\left(25 \mathrm{mM} \mathrm{NaH}_{2} \mathrm{PO}_{4}\right.$ in $25 \% \mathrm{ACN}$, $\mathrm{pH}$ 2.7) and loaded onto a $4.6 \times 250 \mathrm{~mm}$ Ultremex SCX column containing $5-\mu \mathrm{m}$ particles (Phenomenex, California, USA). The peptides were eluted at a flow rate of $1 \mathrm{~mL} / \mathrm{min}$ with a gradient of buffer A for $10 \mathrm{~min}, 5-60 \%$ buffer B $\left(25 \mathrm{mM} \mathrm{NaH}_{2} \mathrm{PO}_{4}, 1 \mathrm{M}\right.$ $\mathrm{KCl}$ in $25 \% \mathrm{ACN}, \mathrm{pH} 2.7$ ) for $27 \mathrm{~min}, 60-100 \%$ buffer $\mathrm{B}$ for $1 \mathrm{~min}$. The system was then maintained at $100 \%$ buffer $B$ for $2 \mathrm{~min}$ before equilibrating with buffer $\mathrm{A}$ for $10 \mathrm{~min}$ prior to the next injection. Elution was monitored by measuring the absorbance at $214 \mathrm{~nm}$, and fractions were collected every $1 \mathrm{~min}$. The eluted peptides were pooled into 12 fractions, desalted with a Strata X C18 column (Phenomenex, California, USA) and vacuum-dried.

\section{LC-ESI-MS/MS Analysis}

According to Zhao et al. (2016), each fraction was resuspended in buffer A ( $5 \% \mathrm{ACN}, 0.1 \% \mathrm{FA})$ and centrifuged at $20,000 \mathrm{~g}$ for $10 \mathrm{~min}$, the final concentration of peptide was about $0.5 \mu \mathrm{g} / \mu \mathrm{L}$ on average. Ten microliters supernatant was loaded on a LC-20AD nano-HPLC (Shimadzu, Kyoto, Japan) by the auto-sampler onto a $2 \mathrm{~cm} \mathrm{C18} \mathrm{trap} \mathrm{column.} \mathrm{Then,} \mathrm{the} \mathrm{peptides} \mathrm{were} \mathrm{eluted} \mathrm{onto}$ a $10 \mathrm{~cm}$ analytical C18 column (inner diameter $75 \mu \mathrm{m}$ ) packed in-house. The samples were loaded at $8 \mu \mathrm{L} / \mathrm{min}$ for $4 \mathrm{~min}$, then the $35 \mathrm{~min}$ gradient was run at $300 \mathrm{~nL} / \mathrm{min}$ starting from 2 to $35 \% \mathrm{~B}(95 \% \mathrm{ACN}, 0.1 \% \mathrm{FA})$, followed by 5 min linear gradient to $60 \%$, then, followed by 2 min linear gradient to $80 \%$, and maintenance at $80 \% \mathrm{~B}$ for $4 \mathrm{~min}$, and finally return to $5 \%$ in $1 \mathrm{~min}$. Data acquisition was performed with a TripleTOF 5600 System (AB Sciex Pte. Ltd., Ontario, Canada) fitted with a Nanospray III source (AB Sciex Pte. Ltd., Ontario, Canada) and a pulled quartz tip as the emitter (New Objectives, Massachusetts, USA). Data was acquired using an ion spray voltage of $2.5 \mathrm{kV}$, curtain gas of $30 \mathrm{psi}$, nebulizer gas of $15 \mathrm{psi}$, and an interface heater temperature of $150^{\circ} \mathrm{C}$. The MS was operated with a reverse phase ( $\geq 30,000$ FWHM) for TOF MS scans. For IDA, survey scans were acquired in $250 \mathrm{~ms}$ and as many as 30 product ion scans were collected if exceeding a threshold of 120 counts per second (counts/s) and with a $2+$ to $5+$ charge-state. Total cycle time was fixed to 3.3 s. Q2 transmission window was $100 \mathrm{Da}$ for $100 \%$. Four time bins were summed for each scan at a pulser frequency value of $11 \mathrm{kHz}$ through monitoring of the $40 \mathrm{GHz}$ multichannel TDC detector with four-anode channel detect ion. A sweeping collision energy setting of $35 \pm 5 \mathrm{eV}$ coupled with iTRAQ adjust rolling collision energy was applied to all precursor ions for collision-induced dissociation. Dynamic exclusion was set for $1 / 2$ of peak width (15s), and then the precursor was refreshed off the exclusion list.

\section{Data Analysis}

Data was analyzed by method proposed by Zhao et al. (2016). Raw data files acquired from the Orbitrap were converted into MGF files using Proteome Discoverer 1.2 (PD 1.2, Thermo), and the MGF files were searched. Proteins identification was performed by using Mascot search engine (Matrix Science, London, UK; version 2.3.02) against the protein translation database containing E. coli O157:H7 sequences. For protein identification, a mass tolerance of $0.05 \mathrm{Da}(\mathrm{ppm})$ was permitted 
for intact peptide masses and 0.1 Da for fragmented ions, with allowance for one missed cleavages in the trypsin digests, Gln>pyro-Glu (N-term Q), Oxidation (M), iTRAQ8plex (Y) as the potential variable modifications, and Carbamidomethyl $(\mathrm{C})$, iTRAQ8plex (N-term), iTRAQ8plex $(\mathrm{K})$ as fixed modifications. The charge states of peptides were set to +2 and +3 . Specifically, an automatic decoy database search was performed in Mascot by choosing the decoy checkbox in which a random sequence of database is generated and tested for raw spectra as well as the real database. To reduce the probability of false peptide identification, only peptides with significance scores $(\geq 20)$ at the $99 \%$ confidence interval by a Mascot probability analysis greater than "identity" were counted as identified. Each confident protein identification involved at least one unique peptide. The GO database (http://www.geneontology.org) and the COG database (http://www.ncbi.nlm.nih.gov/COG/) were used to classify and group the identified proteins. For protein quantitation, it was required that a protein contains at least two unique peptides. The quantitative protein ratios were weighted and normalized by the median ratio in Mascot. For data analysis, $t$-test was used to determine statistical differences, and protein quantification data with relative expression of $>1.5$ and $<0.67$ and $P<0.05$ was chosen to ensure up- and down regulation authenticity. Functional annotations of the DEP were conducted against Uniprot database (http://www.uniprot. org).

\section{RESULTS}

\section{Identification of Proteins}

The iTRAQ method was performed to identify the proteins that were differentially expressed between the SICs and $\mathrm{CK}_{\mathrm{L}}$, or SICs and $\mathrm{CK}_{\mathrm{D}}$. A total of 17,060 unique peptides associated with 2,446 proteins were identified (Table S1). The molecular masses of these proteins were mainly in the range of $10-60 \mathrm{kDa}$ (Figure 1A), and functional classification of the total identified proteins was performed by GO (Figure 1B) and COG analysis (Figure 1C). The 382 proteins were classified into 16 functional categories according to the biological process listed on the GO database. Among these proteins, the top five categories were involved in metabolic process $(36.65 \%)$, cellular process $(27.49 \%)$, biological regulation $(6.81 \%)$, regulation of biological process $(6.81 \%)$ and single-organism process $(6.82 \%)$. The 102 proteins were classified into eight classes according to the cell component in GO database. These proteins were mainly located at cell (31.37\%), cell part (31.37\%), organelle (10.78\%), macromolecular complex $(9.80 \%)$, and membrane $(7.84 \%)$. The 280 proteins were classified into 6 categories according to molecular function in COG database. These proteins mainly involved in catalytic activity (69.28\%) and binding (28.21\%). The 2,446 proteins were classified into 23 COG function categories (Figure 1C). Among these proteins, the top 10 categories were involved in general function prediction only $(11.57 \%)$, amino acid transport and metabolism (9.93\%), transcription (8.30\%), energy production and conversion $(7.71 \%)$, carbohydrate transport and metabolism $(6.77 \%)$, translation, ribosomal structure and biogenesis (6.39\%), signal transduction mechanisms (6.29\%), cell wall/membrane/envelope biogenesis (5.80\%), inorganic ion transport and metabolism (5.42\%).

\section{Functional Classification of Differentially Expressed Proteins (DEP)}

In our study, the iTRAQ reporter ratios of 1.5 - and 0.67 fold $(p<0.05)$ were set as the cut-off value for protein changes. A total of 93 and 29 DEP was found in the SICs compared with $\mathrm{CK}_{\mathrm{L}}$ and $\mathrm{CK}_{\mathrm{D}}$ cells, respectively, and $21 \mathrm{DEP}$ in all the samples (Figure 2A). Detailed information about every DEP was listed in Table 1. Among the 93 DEP in the SICs compared with $\mathrm{CK}_{\mathrm{L}}$, 65 proteins showed down-regulation and 28 showed up-regulation (Figure 3A), and the protein functions were classified into 13 categories according to functional information provided by Uniprot database (Figure 2B). The main functional categories were carbohydrate transport and metabolism (25.81\%), amino acid transport and metabolism (16.13\%), transcription and translation (15.05\%), coenzyme transport and metabolism (6.45\%), DNA replication and repair (5.38\%) and membrane biosynthesis and transport (5.38\%) (Figure 2B). Among the 29 DEP in the SICs compared with $\mathrm{CK}_{\mathrm{D}}, 12$ proteins showed down-regulation and 17 proteins showed up-regulation (Figure 3B), and the protein functions were classified into 10 categories according to functional information provided by Uniprot database (Figure 2C). The main functions categories were carbohydrate transport and metabolism (27.58\%), amino acid transport and metabolism (17.24\%), transcription and translation (13.79\%), and lipid transport and metabolism (10.34\%) (Figure 2C). The 21 common DEP found in both SICs/CK $/ \mathrm{L}_{\mathrm{L}}$ and $\mathrm{SICs} / \mathrm{CK}_{\mathrm{D}}$ were classified into 8 categories according to functional information provided by Uniprot database, and the main categories were carbohydrate transport and metabolism (33.33\%), lipid transport and metabolism (14.28\%), and transcription and translation (19.05\%) (Figure 2D).

\section{DISCUSSION}

\section{Carbohydrate, Lipid, and Amino Acid Transport and Metabolism Related DEP}

In this study, proteins involved in glycolysis, tricarboxylic acid cycle (TCA), glyoxylate cycle, anaerobic respiration, disaccharide metabolism and other processes were downregulated in SICs compared with $\mathrm{CK}_{\mathrm{L}}$ (Table 1), indicating that carbohydrate metabolism in the SICs was inhibited. However, proteins involved in carbohydrate transport and ATP synthesis, including phosphotransferase system (PTS) sugar transporter, ATP synthase F0, C subunit and ATP synthase F1, epsilon subunit, were up-regulated in the SICs compared with $\mathrm{CK}_{\mathrm{L}}$ (Table 1). The PTS is involved in both the transport and phosphorylation of a large number of carbohydrates, known as PTS carbohydrates, in movement toward these carbon sources by the phosphoenolpyruvate (PEP) sensor system (Postma et al., 1993). The up-regulation of PTS sugar transporter in the SICs could enhance the carbohydrate absorption capacity, resulting in the accumulation of carbohydrates in cells, which 

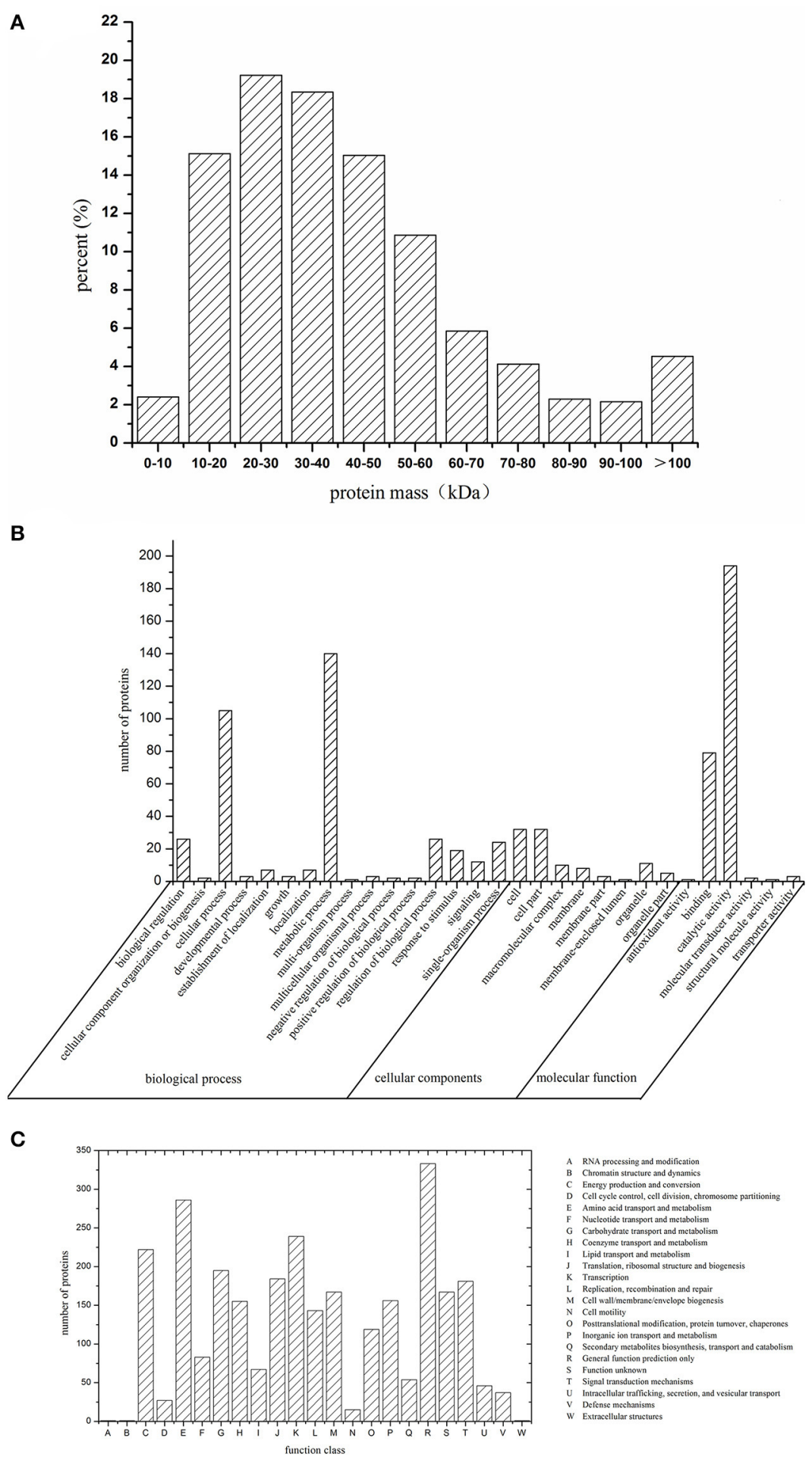

FIGURE 1 | Molecular mass (A), GO classification (B), and COG classification (C) of identified proteins of sublethally injured cells, live cells, and dead cells.

could be a protective agent for the SICs against HPCD stress. ATP synthase produces ATP from ADP in the presence of a proton gradient across the membrane (Guo et al., 2017). The up-regulation of ATP synthase in the SICs might be caused by the $\mathrm{pH}$ lowering effect of $\mathrm{CO}_{2}$ during HPCD treatment, helping establish a transmembrane difference of proton electrochemical potential that the ATP synthase could use to synthesize ATP (Khalimonchuk and Rödel, 2005). The up-regulation of ATP 
A

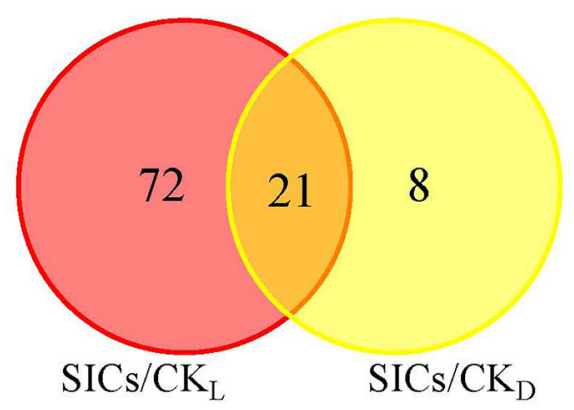

B

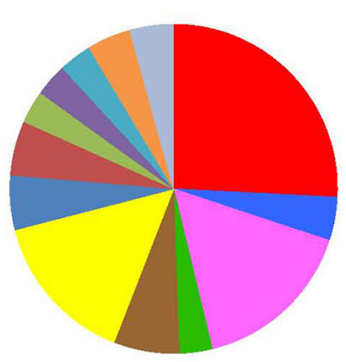

Earbohydrate transport and metabolism $25.81 \%$

口Lipid transport and metabolism $4.3 \%$

=Am ino acid transport and metabolism 16.13\%

-Nucleotide transport and metabolism 3.23\%

- Coenzyme transport and metabolism $6.45 \%$

Transcription and translation $15.05 \%$

— DNA replication and repair $5.38 \%$

Membrane biosynthesis and transport $5.38 \%$

Protein post-translationalmodification and chaperone $3.23 \%$

- Inorganic ion transport $3.23 \%$

asignal transduction $3.23 \%$

- Secretion $4.30 \%$

acell defense $4.30 \%$

\section{$\mathrm{SICs} / \mathrm{CK}_{\mathrm{L}}$}

C

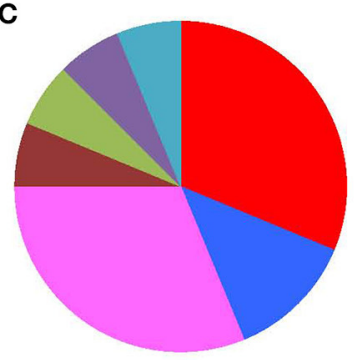

$\mathrm{SICs} / \mathrm{CK}_{\mathrm{D}}$

D

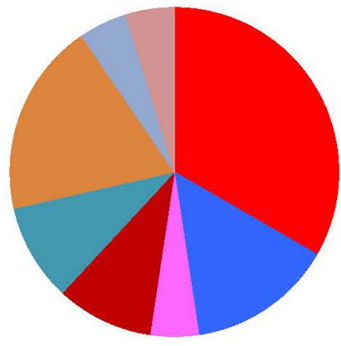

common DEP
- Carbohydrate transport and metabolism $31.25 \%$

- Lipid transport and metabolism $12.5 \%$

Amino acid transport and meta bolism 31.25\%

nCoenzyme transport and metabolism $6.25 \%$

- Protein post-translationa 1 modification and cha perone $6.25 \%$

- Inorganic ion transport $6.25 \%$

m Signal transduction $6.25 \%$
- Carbohydrate transport and metabolism $33.33 \%$

E Lipid transport and metabolism $14.28 \%$

- Amino acid transport and metabolism $4.76 \%$

- Nucleotide transport and meta bolism $9.52 \%$

- Coenzyme transport and meta bolism $9.52 \%$

- Transcription and translation $19.05 \%$

Signal transduction $4.76 \%$

acll defense $4.76 \%$

FIGURE 2 | Venn diagrams of the differentially expressed proteins (A) and functional classifications of these proteins in sublethally injured cells compared with live cells (B), dead cells (C), and proteins in common (D). DEP means differentially expressed proteins; SICs means sublethally injured cells; $C_{L} K_{L}$ means control of live cells; $\mathrm{CK}_{\mathrm{D}}$ means control of dead cells. 
TABLE 1 | Differentially expressed proteins in sublethally injured cells induced by high pressure carbon dioxide treatment.

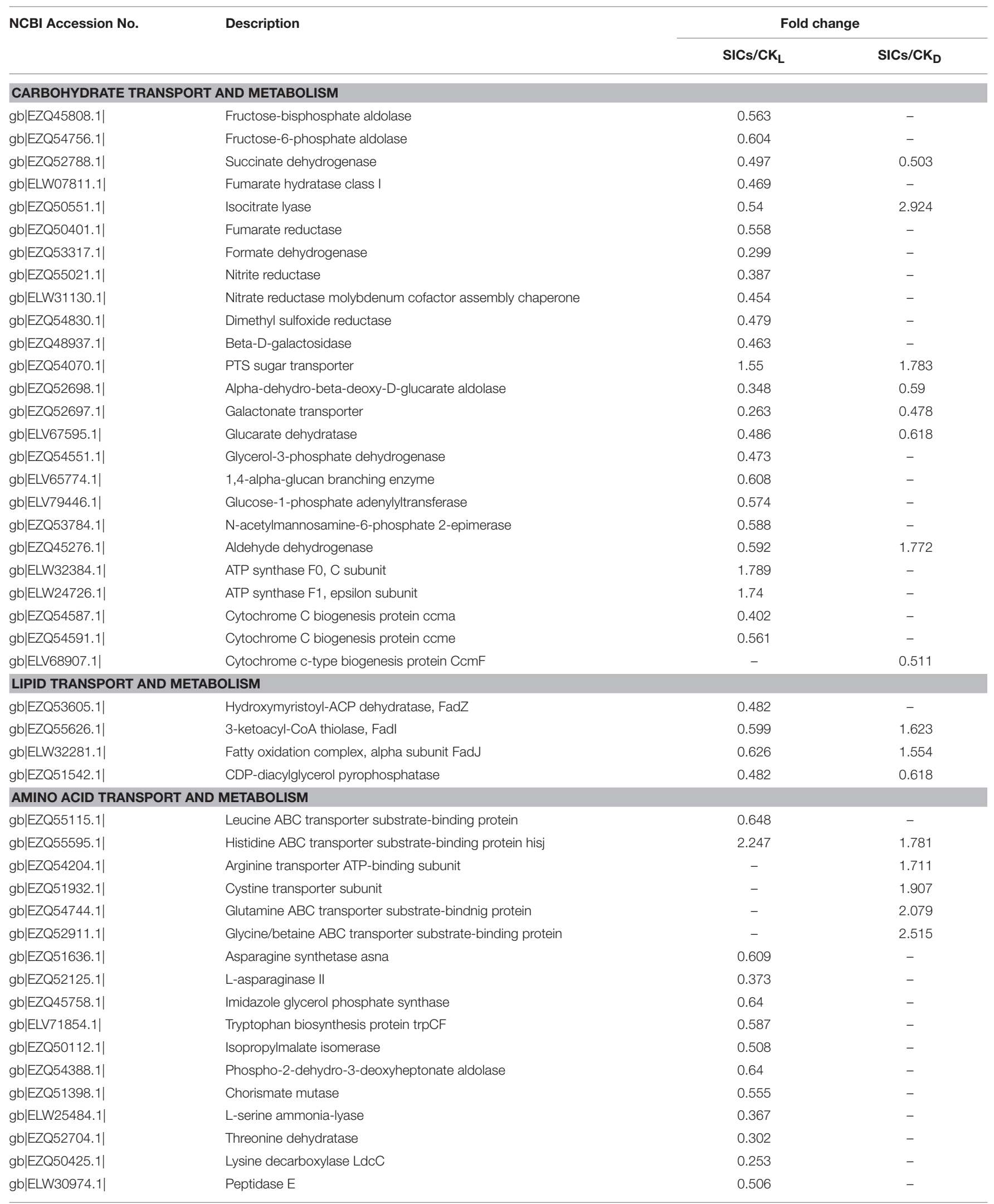


TABLE 1 | Continued

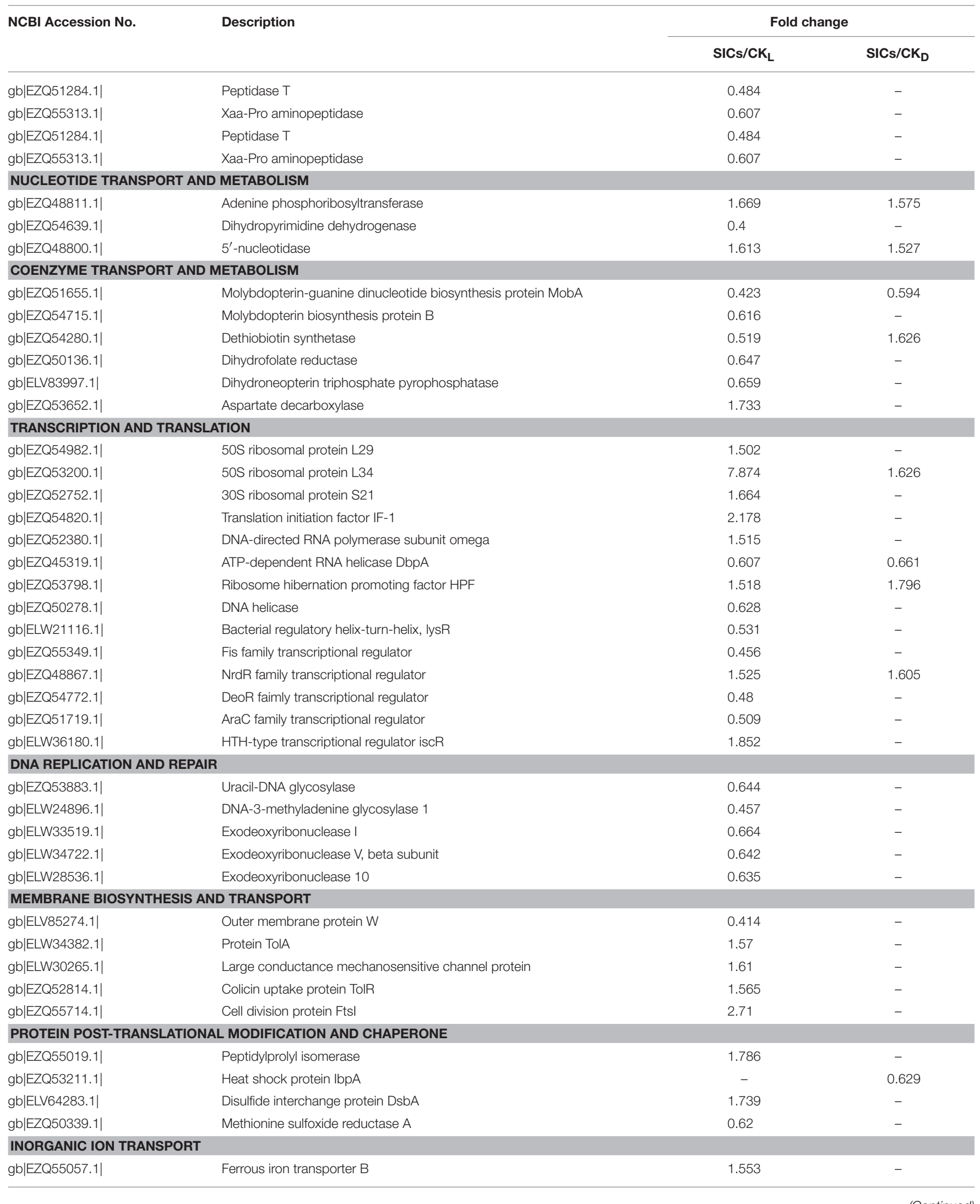


TABLE 1 | Continued

\begin{tabular}{|c|c|c|c|}
\hline NCBI Accession No. & Description & \multicolumn{2}{|c|}{ Fold change } \\
\hline gb|EZQ52832.1| & Molybdate transporter & - & 0.623 \\
\hline gb|ELW31127.1| & Nitrite extrusion protein 1 & 0.38 & - \\
\hline \multicolumn{4}{|c|}{ SIGNAL TRANSDUCTION } \\
\hline gb|EZQ51547.1| & Universal stress protein UspD & 1.582 & - \\
\hline gb|ELW36511.1| & Inner membrane protein YjiY & 0.481 & - \\
\hline gb|ELW38901.1| & Sensor protein KdpD & 0.608 & 0.629 \\
\hline \multicolumn{4}{|l|}{ SECRETION } \\
\hline gb|EZQ53138.1| & Preprotein translocase subunit SecA & 1.527 & - \\
\hline gb|EZQ51533.1| & Superoxide dismutase & 2.433 & - \\
\hline gb|EZQ55206.1| & Cytochrome C peroxidase & 0.381 & - \\
\hline gb|EZQ54745.1| & DNA starvation/stationary phase protection protein Dps & 0.523 & - \\
\hline gb|EZQ51542.1| & Undecaprenyl-diphosphatase OS & 0.633 & 0.618 \\
\hline
\end{tabular}

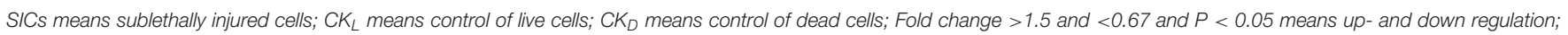
-means no significant fold change.

synthase in the SICs could intake extracellular proton and make a membrane balance of protons, thus protecting the SICs against HPCD stress. Compared with $\mathrm{CK}_{\mathrm{D}}, 5$ carbohydrate metabolism related proteins were down-regulated in the SICs (Table 1). The down-regulation of these proteins indicated that the SICs were in a dormant-like state with a relatively low carbohydrate metabolism activity, which could improve the survival of these cells under HPCD stress. Isocitrate lyase (ICL) and PTS sugar transporter was up-regulated in the SICs compared with $\mathrm{CK}_{\mathrm{D}}$ (Table 1). ICL catalyzes the reversible formation of succinate and glyoxylate from isocitrate, a key step of the glyoxylate cycle, which operates as an anaplerotic route for replenishing the oxaloacetate in TCA (Ornston and Ornston, 1969). The decarboxylation of oxaloacetate is the initial step of gluconeogenesis at the phosphoenolpyruvate-pyruvate-oxaloacetate node (Sauer and Eikmanns, 2005). The up-regulation of ICL might enhance the gluconeogenesis in the SICs compared with $\mathrm{CK}_{\mathrm{D}}$, resulting in the increase of glucose content in the SICs. Meanwhile, the up-regulation of PTS sugar transporter could also increase the sugar contents in the SICs. These results indicated that sugar accumulation and low carbohydrate degradation activity might be an important protective strategy for the SICs against HPCD stress.

Proteins involved in lipid synthesis, lipid degradation and phospholipid metabolism, including hydroxymyristoylACP dehydratase (FabZ), 3-ketoacyl-CoA thiolase (FadI), fatty oxidation complex, alpha subunit (FadJ) and CDP-diacylglycerol pyrophosphatase (CDAGP) were down-regulated in the SICs compared with $\mathrm{CK}_{\mathrm{L}}$. FadJ and FadI were up-regulated, but CDAGP was down-regulated in the SICs compared with
$\mathrm{CK}_{\mathrm{D}}$ (Table 1). FabZ efficiently catalyzes the dehydration of short chain b-hydroxyacyl-ACPs and long chain saturated and unsaturated b-hydroxyacyl-ACPs in the dissociated, type II fatty acid biosynthesis (Heath and Rock, 1996). The down-regulation of FabZ in the SICs indicated that the lipid synthesis of the SICs might be inhibited. Both FadJ and FadI are involved in fatty acid beta-oxidation: FadJ catalyzes the formation of a hydroxyacyl-CoA by addition of water on enoyl-CoA, and FadI catalyzes the final step of fatty acid oxidation in which acetyl-CoA is released and the CoA ester of a fatty acid two carbons shorter is formed (Campbell et al., 2003). FadJ and FadI were down-regulated in the SICs when compared with $\mathrm{CK}_{\mathrm{L}}$, but were up-regulated when compared with $\mathrm{CK}_{\mathrm{D}}$, indicating the lipid degradation of the SICs was decreased by HPCD treatment. CDAGP synthesizes phosphatidate from CDP-diacylglycerol, which is part of phospholipid metabolism (Icho et al., 1985). The down-regulation of CDAGP in the SICs might result in less phospholipid synthesis. Overall, these results indicated that the lipid transport and metabolism in the SICs were decreased, and the low metabolic activity might improve the survival of these cells under HPCD stress.

Compared with $\mathrm{CK}_{\mathrm{L}}$, proteins involved in amino acid transport, amino acid synthesis and amino degradation, except for histidine $\mathrm{ABC}$ transporter substrate-binding protein HisJ, were down-regulated in the SICs (Table 1), indicating that amino acid transport and metabolism in the SICs might be decreased. However, proteins involved in amino acid transport, including histidine ABC transporter substrate-binding protein HisJ, arginine transporter ATP-binding subunit, cystine transporter 

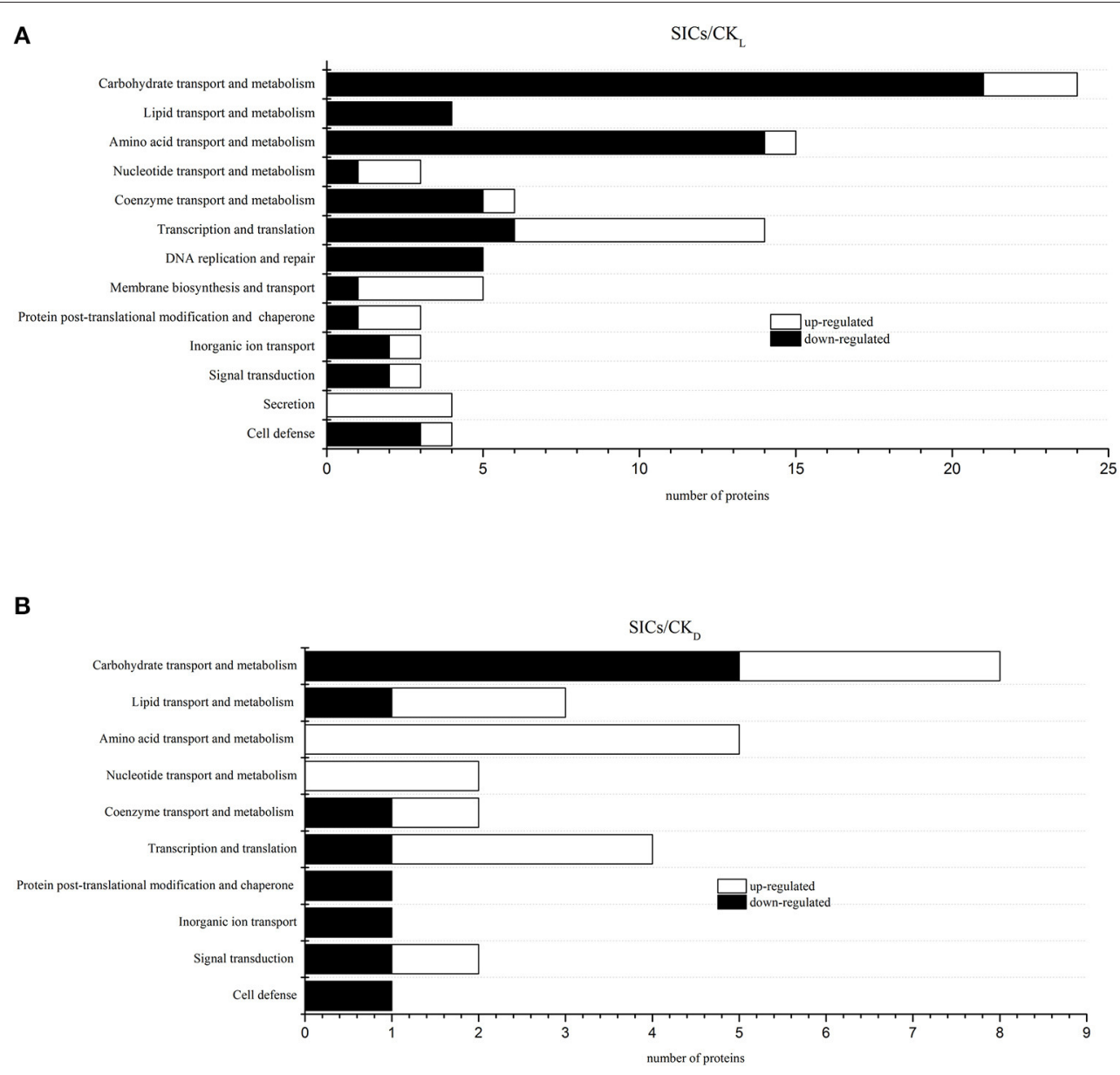

FIGURE 3 | Classification of differentially expressed proteins in sublethally injured cells compared with live cells (A) and dead cells (B). SICs means sublethally injured cells; $\mathrm{CK}_{\mathrm{L}}$ means control of live cells; $\mathrm{CK}_{\mathrm{D}}$ means control of dead cells.

subunit, glutamine $\mathrm{ABC}$ transporter substrate-binding protein, glycine/betaine $\mathrm{ABC}$ transporter substrate-binding protein, were up-regulated in the SICs compared with $\mathrm{CK}_{\mathrm{D}}$ (Table 1). ATP binding cassette $(\mathrm{ABC})$ transporters is a large class of transporters that are responsible for the ATP powered translocation of many substrates across membranes, besides, $\mathrm{ABC}$ transporters mainly function as importers in prokaryotes, where they mediate the uptake of essential nutrients, such as amino acids, sugars, and essential metals (Rees et al., 2009). The up-regulation of these $\mathrm{ABC}$ transporters might result in more amino acids importing into the SICs. Amino acids could function as protective agent and repair material for the SICs (Bi et al., 2015). Therefore, the differences in the expression of these $\mathrm{ABC}$ transporters between the SICs and dead cells might contribute to the survival of the SICs under HPCD stress.

\section{Nucleotide, Coenzyme Transport, and Metabolism Related DEP}

Adenine phosphoribosyltransferase (APT) and $5^{\prime}$-nucleotidase were up-regulated in the SICs compared with $\mathrm{CK}_{\mathrm{L}}$ and $\mathrm{CK}_{\mathrm{D}}$ (Table 1). APT catalyzes a reaction between adenine and 5-phosphoribosyl-1-pyrophosphate (PRPP) to produce adenosine monophosphate (AMP) and pyrophosphate, providing an alternative way of making AMP rather than synthesizing purine nucleotides de novo (Sin and Finch, 1972). The up-regulation of APT could provide AMP for the SICs in an energy-saving way. Dihydropyrimidine dehydrogenase (PRE) was down-regulated in the SICs compared with $\mathrm{CK}_{\mathrm{L}}$ (Table 1). PRE is involved in pyrimidine base degradation, and it catalyzes physiologically the reduction of uracil to 5,6-dihydrouracil (DHU) and the reduction of thymine to 5,6-dihydrothymine (DHT) by using NADH as a specific cosubstrate (Hidese et al., 2011). The down-regulation of PRE could result in less pyrimidine base degradation in the SICs, which was in accordance with the dormant state of low biological activity of the SICs.

Proteins involved in Mo-molybdopterin guanine dinucleotide (Mo-MGD) cofactor biosynthesis, folic acid synthesis and biotin synthesis were down-regulated in the SICs compared with $\mathrm{CK}_{\mathrm{L}}$ (Table 1). Molybdopterin-guanine dinucleotide biosynthesis protein (MobA) can transfer a GMP moiety from GTP to Mo-molybdopterin (Mo-MPT) cofactor (Moco or molybdenum 
cofactor) to form Mo-MGD cofactor and inorganpyrophosphate (Palmer et al., 1994). Molybdopterin biosynthesis protein B (MobB) is not required for the biosynthesis of Mo-MGD cofactor, and not necessary for the formation of active molybdoenzymes, but may act as an adapter protein to achieve the efficient biosynthesis and utilization of MGD (McLuskey et al., 2003). The down-regulation of MobA and MobB may decrease the transfer from GTP to GMP, resulting in less energy release, which was in accordance with the decreased energy demand of the SICs. Dethiobiotin synthetase (BioD) was down-regulated in the SICs when compared with $\mathrm{CK}_{\mathrm{L}}$, but was up-regulated when compared with $\mathrm{CK}_{\mathrm{D}}$ (Table 1). BioD can synthesize dethiobiotin from 7,8-diaminononanoate, which is part of the pathway biotin biosynthesis (Krell and Eisenberg, 1970). The down-regulation of $\mathrm{BioD}$ might decrease the biosynthesis of biotin, which may further reduce carbohydrate, lipid and protein metabolism since biotin was an important co-factor for carboxylases. These results indicated that the SICs might have a lower biotin synthesis capacity than the $\mathrm{CK}_{\mathrm{L}}$, but a higher biotin synthesis capacity than the $\mathrm{CK}_{\mathrm{D}}$. Dihydrofolate reductase (FolA) and dihydroneopterin triphosphate pyrophosphatase (NUDB) are key enzymes in folate metabolism: FolA synthesizes 5,6,7,8-tetrahydrofolate from 7,8-dihydrofolate (Iwakura et al., 2006); NUDB catalyzes the hydrolysis of dihydroneopterin triphosphate to dihydroneopterin monophosphate and pyrophosphate (Gabelli et al., 2007). The down-regulation of FolA and NUDB might decrease the biosynthesis of folate, which may further reduce amino acid and nucleotide synthesis since folate was an important co-factor for one carbon unit transferases.

\section{Transcription and Translation, DNA Replication, and Repair Related DEP}

Proteins involved in rRNA binding or functioned as structural constituent of ribosome, including 50S ribosomal protein L29, 50 S ribosomal protein L34 and 30S ribosomal protein S21, were up-regulated in the SICs compared with $\mathrm{CK}_{\mathrm{L}}$. Ribosome hibernation promoting factor (HPF) was up-regulated while ATP-dependent RNA helicase (DbpA) was down-regulated in the SICs compared with $\mathrm{CK}_{\mathrm{L}}$ and $\mathrm{CK}_{\mathrm{D}}$ (Table 1). DbpA is involved in the assembly of the 50S ribosomal subunit, which has an RNA-dependent ATPase activity for 23S rRNA, and a $3^{\prime}$ to $5^{\prime}$ RNA helicase activity that uses the energy of ATP hydrolysis to destabilize and unwind short rRNA duplexes (Fuller-Pace et al., 1993). The down-regulation of DbpA indicated that the assembly of the 50S ribosomal submits might be decreased. As a negative regulation factor of translation, HPF can promote and stabilize dimerization of $70 \mathrm{~S}$ ribosomes by the ribosome modulation factor (RMF), leading to the formation of inactive $100 \mathrm{~S}$ ribosomes during stationary phase (Ueta et al., 2008). The up-regulation of HPF suggested that the ribosomes activity of the SICs might be inactive. These results showed that the translation activity of the SICs might be decreased although ribosomal proteins were up-regulated, which was in agreement with the dormant state with low biological activity of the SICs.
As shown in Table 1, transcription promoters including bacterial regulatory helix-turn-helix (LysR), Fis family transcriptional regulator (Fis), and $\mathrm{AraC}$ family transcriptional regulator (AraC) were down-regulated while transcription repressor including $\mathrm{NrdR}$ family transcriptional regulator (NrdR) and HTH-type transcriptional regulator (IscR) were up-regulated in the SICs compared with $\mathrm{CK}_{\mathrm{L}}$. NrdR was also up-regulated in the SICs compared with $\mathrm{CK}_{\mathrm{D}}$. LysR activates the transcription of the lysA gene encoding diaminopimelate decarboxylase and is also a negative regulator of its own expression (Stragier and Patte, 1983). Fis activates ribosomal RNA transcription, which plays a direct role in upstream activation of rRNA promoters, and can bind to a recombinational enhancer sequence required to stimulate hin-mediated DNA inversion (Ross et al., 1990). Fis can also prevent initiation of DNA replication from oriC to ensure the efficiency of transcription (Wold et al., 1996). AraC controls the expression of at least six genes involved in the transport and catabolism of L-arabinose and regulates initiation of transcription of the araBAD operon and its own synthesis (Soisson et al., 1997). The down-regulation of LysR, Fis, and AraC indicated that the transcription of the lysA gene, ribosomal RNA, and araBAD operon might be decreased. As transcriptional repressor, $\mathrm{NrdR}$ differentially regulates transcription of $n r d A B, n r d H I E F$, and $n r d D$ genes encoding ribonucleotide reductase in aerobic growth by binding to $\mathrm{NrdR}$ boxes in the promoter regions to alter promoter activity (Torrents et al., 2007). IscR is a transcriptional repressor of the iscRSUA operon, which is involved in the assembly of Fe-S clusters into Fe-S proteins (Schwartz et al., 2001). The up-regulation of $\mathrm{NrdR}$ and IscR might cause the transcription of NrdR boxes and iscRSUA operon decreasing. These results indicated that the transcription activity of the SICs might be decreased. During transcription, the double chain of DNA was revealed and exposed to the environment, which may increase the damage to nucleic acid under stress conditions. The decrease in transcription activity of the SICs may result in a highly compressed helical DNA, which could avoid severe damage from HPCD stress and induce the cells entry into a dormant state to survive.

Proteins involved in DNA replication and repair were all down-regulated in the SICs compared with $\mathrm{CK}_{\mathrm{L}}$ (Table 1), indicating the SICs had a lower DNA replication and repair activity. Similar results were found by others (Wu et al., 2012; Wang et al., 2016). Wang et al. (2016) found that all proteins in related to DNA replication and transcription in S. aureus cells were down-regulated after treatment with juglone for $2 \mathrm{~h}$. $\mathrm{Wu}$ et al. (2012) found that four proteins involved in DNA replication of Lactobacillus casei were down-regulated to lactic acid treatment at $\mathrm{pH}$ 3.5. The decrease in DNA replication might have a protective effect on the nuclear region while the decrease in repair activity might induce more mutation, which might have a higher resistance to the HPCD stress and survive. Since the SICs induced by HPCD had a low capacity in DNA replication and repair, some technologies (e.g., UV; gamma irradiation; plasma) targeted to action on the DNA might easily kill the SICs, which may open up the possibility of combination HPCD and these technologies as hurdle approaches for food preservation. 


\section{Membrane Biosynthesis and Inorganic Ion Transport Related DEP}

Proteins involved in membrane biosynthesis, except for outer membrane protein $\mathrm{W}(\mathrm{OmpW})$, were up-regulated in the SICs compared with $\mathrm{CK}_{\mathrm{L}}$ (Table 1). Large conductance mechanosensitive channel protein (MSCL) forms a nonselective ion channel with a conductance of about 4 nanosiemens, which will open in response to a pressure causing sublethal injury in the membrane, to avoid cell disruption and death (Sukharev et al., 1994). The up-regulation of MSCL indicated that the SICs had a pressure response to HPCD treatment. Colicin uptake protein TolR (TolR) and protein TolA (TolA) are involved in the TonB-independent uptake of group A colicins (colicins A, E1, E2, E3, and K) (Kampfenkel and Braun, 1993). The up-regulation of TolR and TolA may increase the transport of group A colicins in The SICs. Cell division protein FtsI (FtsI) is involved in the pathway peptidoglycan biosynthesis, which catalyzes crosslinking of the peptidoglycan cell wall at the division septum (Ishino and Matsuhashi, 1981). The up-regulation of FtsI in the SICs could increase the cross-linking of peptidoglycan, which might be a response to the high pressure under HPCD treatment.

Ferritin (FTNA) and nitrite extrusion protein 1 (NarK) was down-regulated in the SICs compared with $\mathrm{CK}_{\mathrm{L}}$ while molybdate transporter was down-regulated in the SICs compared with $\mathrm{CK}_{\mathrm{D}}$ (Table 1). The down-regulation of these proteins might decrease the transport of some inorganic ion such as iron, molybdate, and nitrite. However, ferrous iron transporter $\mathrm{B}$ (FEOB) was up-regulated in the SICs compared with $\mathrm{CK}_{\mathrm{L}}$. FEOB is a transporter of a GTP-driven $\mathrm{Fe}^{2+}$ uptake system and a stimulus of cellular response to DNA damage (Marlovits et al., 2002). The up-regulation of FEOB might increase the intake of $\mathrm{Fe}^{2+}$ in the SICs or be a response to DNA damage under HPCD stress.

\section{DEP Involved in Other Processes}

Among the DEP involved in protein post-translational modification and chaperone, heat shock protein IbpA was down-regulated in the SICs compared with $\mathrm{CK}_{\mathrm{D}}$, while disulfide interchange protein (DsbA) was up-regulated in the SICs compared with $\mathrm{CK}_{\mathrm{L}}$ (Table 1). IbpA is associated with aggregated proteins, together with $\mathrm{IbpB}$, to stabilize and protect them from irreversible denaturation and extensive proteolysis during heat shock and oxidative stress (Kuczynska-Wiśnik et al., 2002). The down-regulation of IbpA in the SICs under HPCD stress might be caused by the low temperature and anaerobic environment during HPCD treatment, which would not trigger the IbpA expression. DsbA is required for disulfide bond formation in some periplasmic proteins such as PhoA or OmpA and actes by transferring its disulfide bond to other proteins and itself is reduced in the process (Kishigami et al., 1995). The up-regulation of DsbA might increase the formation of disulfide bond in outer membrane protein, which could improve the stability of outer membrane protein and thus contribute to survival of the SICs under HPCD stress.

Among the DEP involved in signal transduction, carbon starvation protein A (CSTA) and universal stress protein UspD
(USPD) were up-regulated in the SICs compared with $\mathrm{CK}_{\mathrm{D}}$ and $\mathrm{CK}_{\mathrm{L}}$, respectively (Table 1 ). CSTA can utilize peptide during carbon starvation, which is a stress response of cell to starvation (Schultz and Matin, 1991). The up-regulation of CSTA might increase the breaking down of peptide to amino acids, which could act as cell protection agent under stress. USPD is required for resistance to DNA-damaging agents and its expression can be induced by starvation, heat shock and toxicants (Bochkareva et al., 2002). The up-regulation of USPD could improve the resistance of the SICs to DNA damage by HPCD treatment.

Among the DEP involved in cell defense, superoxide dismutase (SOD) was up-regulated while cytochrome $\mathrm{C}$ peroxidase (YHJA) and DNA starvation/stationary phase protection protein (DPS) was down-regulated in the SICs compared with $\mathrm{CK}_{\mathrm{L}}$ (Table 1). SOD can defend against the toxicity of superoxide by scavenge it with hydrogen ion to form oxygen and hydrogen peroxide (Imlay and Imlay, 1996). YHJA can catalyze hydrogen peroxide and ferrocytochrome c to form water and ferricytochrome c (Partridge et al., 2007). The up-regulation of SOD and down-regulation of YHJA indicated that the SICs had an increased SOD radical destroying capacity but a decreased YHJA radical destroying capacity. DPS can bind the chromosome non-specifically, forming a highly ordered and stable dps-DNA co-crystal within which chromosomal DNA is condensed and protected from diverse damages, including oxidative damage, UV and gamma irradiation, iron and copper toxicity, thermal stress and acid and base shocks (Nair and Finkel, 2004). The down-regulation of DPS indicated that the SICs had a lower protection capacity to DNA damage, which was in agreement with that the SICs had a lower DNA repair capacity. The sublethal injury in DNA could result in some mutations, which might have a higher resistance to the HPCD stress and survive.

Proteins involved in secretion were all up-regulated in the SICs compared with $\mathrm{CK}_{\mathrm{L}}$ (Table 1), indicating that the SICs might have a higher protein secretion capacity. However, the physiological function of the increased secretion was unknown, which needed further study to confirm.

\section{CONCLUSION}

We explored the molecular basis involved in the formation of sublethally injured E. coli O157:H7 induced by HPCD using iTRAQ proteomic methods. The changes in protein expression might be associated with pathways contributing to the formation of the SICs and their survival. Firstly, the SICs showed stress response to HPCD, with an increase of carbohydrate transport, peptidoglycan synthesis and disulfide bond formation, which could function as a barrier protecting the cells against environmental stresses. Secondly, the SICs showed DNA damage response to HPCD, with a decreased DNA repair capacity, which might generate more mutations with a higher resistance to HPCD and survive. Thirdly, activities of main metabolic processes as carbohydrate and 
nucleotide decomposing, transport and metabolism of lipid, amino acid and coenzyme were decreased, and transcription, translation and DNA replication were repressed during formation of The SICs. In conclusion, decreased metabolic activity, repressed cell division and enhanced survival ability in E. coli O157:H7 might cause the formation of the SICs under HPCD.

\section{AUTHOR CONTRIBUTIONS}

XB: Carrying out the experiments and writing the manuscript; YW: Giving advice and assistance for the experiment; $\mathrm{XH}$ : Reviewing the manuscript and giving advice; XL: Designing the experiment and reviewing the manuscript.

\section{REFERENCES}

Bi, X., Wang, Y., Zhao, F., Sun, Z., Hu, X., and Liao, X. (2015). Sublethal injury and recovery of Escherichia coli O157: H7 by high pressure carbon dioxide. Food Control 50, 705-713. doi: 10.1016/j.foodcont.2014.10.014

Bi, X., Wang, Y., Zhao, F., Zhang, Y., Rao, L., Liao, X., et al. (2014). Inactivation of Escherichia coli O157: H7 by high pressure carbon dioxide combined with nisin in physiological saline, phosphate-buffered saline and carrot juice. Food Control 41, 139-146. doi: 10.1016/j.foodcont.2014.01.012

Bochkareva, E. S., Girshovich, A. S., and Bibi, E. (2002). Identification and characterization of the Escherichia coli stress protein UP12, a putative in vivo substrate of GroEL. FEBS J. 269, 3032-3040. doi: 10.1046/j.1432-1033.2002.02978.x

Campbell, J. W., Morgan-Kiss, R. M., and Cronan, J. E. Jr. (2003). A new Escherichia coli metabolic competency: growth on fatty acids by a novel anaerobic $\beta$-oxidation pathway. Mol. Microbiol. 47, 793-805. doi: 10.1046/j.1365-2958.2003.03341.x

Fuller-Pace, F. V., Nicol, S. M., Reid, A. D., and Lane, D. P. (1993). DbpA: a DEAD box protein specifically activated by 23s rRNA. EMBO J. 12, 3619-3626.

Gabelli, S. B., Bianchet, M. A., Xu, W., Dunn, C. A., Niu, Z. D., Amzel, L. M., et al. (2007). Structure and function of the E. coli dihydroneopterin triphosphate pyrophosphatase: a Nudix enzyme involved in folate biosynthesis. Structure 15, 1014-1022. doi: 10.1016/j.str.2007.06.018

Garcia-Gonzalez, L., Geeraerd, A. H., Spilimbergo, S., Elst, K., Van Ginneken, L., Debevere, J., et al. (2007). High pressure carbon dioxide inactivation of microorganisms in foods: the past, the present and the future. Int. J. Food Microbiol. 117, 1-28. doi: 10.1016/j.ijfoodmicro.2007.02.018

Guo, L., Gu, Z., Jin, X., and Yang, R. (2017). iTRAQ-based proteomic and physiological analyses of broccoli sprouts in response to the stresses of heat, hypoxia and heat plus hypoxia. Plant Soil 414, 355-377. doi: 10.1007/s11104-016-3132-6

Heath, R. J., and Rock, C. O. (1996). Roles of the FabA and FabZ $\beta$ hydroxyacyl-acyl carrier protein dehydratases in Escherichia coli fatty acid biosynthesis. J. Biol. Chem. 271, 27795-27801. doi: 10.1074/jbc.271.44. 27795

Heiman, K. E., Mody, R. K., Johnson, S. D., Griffin, P. M., and Gould, L. H. (2015). Escherichia coli O157 outbreaks in the United States, 2003-2012. Emerging Infect. Dis. 21, 1293-1301. doi: 10.3201/eid2108.141364

Hidese, R., Mihara, H., Kurihara, T., and Esaki, N. (2011). Escherichia coli dihydropyrimidine dehydrogenase is a novel NAD-dependent heterotetramer essential for the production of 5, 6-dihydrouracil. J. Bacteriol. 193, 989-993. doi: 10.1128/JB.01178-10

Icho, T., Bulawa, C. E., and Raetz, C. R. (1985). Molecular cloning and sequencing of the gene for CDP-diglyceride hydrolase of Escherichia coli. J. Biol. Chem. 260, 12092-12098.

Imlay, K. R., and Imlay, J. A. (1996). Cloning and analysis of sodC, encoding the copper-zinc superoxide dismutase of Escherichia coli. J. Bacteriol. 178, 2564-2571. doi: 10.1128/jb.178.9.2564-2571.1996

\section{ACKNOWLEDGMENTS}

This work, including the efforts of $\mathrm{XL}$, was supported by project of National Natural Science Foundation of China (NSFC) (No. 31571933), "Beijing Training Project for the Leading Talents in S\&T" (No. Z151100000315032) and "Agricultural Scientific Research Outstanding Talent Training Project” (No. 201605210610623).

\section{SUPPLEMENTARY MATERIAL}

The Supplementary Material for this article can be found online at: https://www.frontiersin.org/articles/10.3389/fmicb. 2017.02544/full\#supplementary-material

Ishino, F., and Matsuhashi, M. (1981). Peptidoglycan synthetic enzyme activities of highly purified penicillin-binding protein 3 in Escherichia coli: a septumforming reaction sequence. Biochem. Biophys. Res. Commun. 101, 905-911. doi: 10.1016/0006-291X(81)91835-0

Iwakura, M., Maki, K., Takahashi, H., Takenawa, T., Yokota, A., Katayanagi, K., et al. (2006). Evolutional design of a hyperactive cysteine-and methioninefree mutant of Escherichia coli dihydrofolate reductase. J. Biol. Chem. 281, 13234-13246. doi: 10.1074/jbc.M508823200

Jin, X., Yang, R., Guo, L., Wang, X., Yan, X., and Gu, Z. (2017). iTRAQ analysis of low-phytate mung bean sprouts treated with sodium citrate, sodium acetate and sodium tartrate. Food Chem. 218, 285-293. doi: 10.1016/j.foodchem.2016.09.029

Kampfenkel, K., and Braun, V. (1993). Membrane topologies of the TolQ and TolR proteins of Escherichia coli: inactivation of TolQ by a missense mutation in the proposed first transmembrane segment. J. Bacteriol. 175, 4485-4491. doi: 10.1128/jb.175.14.4485-4491.1993

Khalimonchuk, O., and Rödel, G. (2005). Biogenesis of cytochrome c oxidase. Mitochondrion 5, 363-388. doi: 10.1016/j.mito.2005.08.002

Kilimann, K. V., Hartmann, C., Delgado, A., Vogel, R. F., and Gänzle, M. G. (2006). Combined high pressure and temperature induced lethal and sublethal injury of Lactococcus lactis-Application of multivariate statistical analysis. Int. J. Food Microbiol. 109, 25-33. doi: 10.1016/j.ijfoodmicro.2006.01.006

Kishigami, S., Kanaya, E., Kikuchi, M., and Ito, K. (1995). DsbA-DsbB interaction through their active site cysteines evidence from an odd cysteine mutant of DsbA. J. Biol. Chem. 270, 17072-17074. doi: 10.1074/jbc.270.29. 17072

Krell, K., and Eisenberg, M. A. (1970). The purification and properties of dethiobiotin synthetase. J. Biol. Chem. 245, 6558-6566.

Kuczynska-Wiśnik, D., Kçdzierska, S., Matuszewska, E., Lund, P., Taylor, A., Lipinska, B., et al. (2002). The Escherichia coli small heat-shock proteins IbpA and $\mathrm{IbpB}$ prevent the aggregation of endogenous proteins denatured in vivo during extreme heat shock. Microbiology 148, 1757-1765. doi: 10.1099/00221287-148-6-1757

Li, J., Suo, Y., Liao, X., Ahn, J., Liu, D., Chen, S., et al. (2017). Analysis of Staphylococcus aureus cell viability, sublethal injury and death induced by synergistic combination of ultrasound and mild heat. Ultrason. Sonochem. 39, 101-110. doi: 10.1016/j.ultsonch.2017.04.019

Liao, H., Hu, X., Liao, X., Chen, F., and Wu, J. (2007). Inactivation of Escherichia coli inoculated into cloudy apple juice exposed to dense phase carbon dioxide. Int. J. Food Microbiol. 118, 126-131. doi: 10.1016/j.ijfoodmicro.2007.06.018

Liao, H., Zhang, F., Hu, X., and Liao, X. (2011). Effects of high-pressure carbon dioxide on proteins and DNA in Escherichia coli. Microbiology 157, 709-720. doi: 10.1099/mic.0.046623-0

Marder, E. P., Garman, K. N., Ingram, L. A., and Dunn, J. R. (2014). Multistate outbreak of Escherichia coli O157: H7 associated with bagged salad. Food Borne Pathog. Dis. 11, 593-595. doi: 10.1089/fpd.2013.1726

Marlovits, T. C., Haase, W., Herrmann, C., Aller, S. G., and Unger, V. M. (2002). The membrane protein FeoB contains an intramolecular $G$ protein essential 
for Fe (II) uptake in bacteria. Proc. Natl. Acad. Sci. U.S.A. 99, 16243-16248. doi: 10.1073/pnas.242338299

McLuskey, K., Harrison, J. A., Schüttelkopf, A. W., Boxer, D. H., and Hunter, W. N. (2003). Insight into the role of Escherichia coli MobB in molybdenum cofactor biosynthesis based on the high resolution crystal structure. J. Biol. Chem. 278, 23706-23713. doi: 10.1074/jbc.M301485200

Molina-Höppner, A., Doster, W., Vogel, R. F., and Gänzle, M. G. (2004). Protective effect of sucrose and sodium chloride for Lactococcus lactis during sublethal and lethal high-pressure treatments. Appl. Environ. Microbiol. 70, 2013-2020. doi: 10.1128/AEM.70.4.2013-2020.2004

Nair, S., and Finkel, S. E. (2004). Dps protects cells against multiple stresses during stationary phase. J. Bacteriol. 186, 4192-4198. doi: 10.1128/JB.186.13.4192-4198.2004

Ornston, L. N., and Ornston, M. K. (1969). Regulation of glyoxylate metabolism in Escherichia coli K-12. J. Bacteriol. 98, 1098-1108.

Palmer, T., Vasishta, A., Whitty, P. W., and Boxer, D. H. (1994). Isolation of protein FA, a product of the mob locus required for molybdenum cofactor biosynthesis in Escherichia coli. FEBS J. 222, 687-692. doi: 10.1111/j.1432-1033.1994.tb18913.x

Pandhal, J., Ow, S. Y., Noirel, J., and andWright, P. C. (2011). Improving Nglycosylation efficiency in Escherichia coli using shotgun proteomics, metabolic network analysis, and selective reaction monitoring. Biotechnol. Bioeng. 108, 902-912. doi: 10.1002/bit.23011

Partridge, J. D., Poole, R. K., and Green, J. (2007). The Escherichia coli yhjA gene, encoding a predicted cytochrome c peroxidase, is regulated by FNR and OxyR. Microbiology 153, 1499-1509. doi: 10.1099/mic.0.2006/004838-0

Phillips, C. A. (1999). The epidemiology, detection and control of Escherichia coli O157. J. Sci. Food Agric. 79, 1367-1381. doi: 10.1002/(SICI)1097-0010(199908)79:11<1367::AID-JSFA374>3.0.CO;2-S

Postma, P. W., Lengeler, J. W., and Jacobson, G. R. (1993). Phosphoenolpyruvate: carbohydrate phosphotransferase systems of bacteria. Microbiol. Mol. Biol. Rev. 57, 543-594.

Rees, D. C., Johnson, E., and Lewinson, O. (2009). ABC transporters: the power to change. Nat. Rev. Mol. Cell Bio. 10, 218-227. doi: 10.1038/nrm2646

Riley, L. W., Remis, R. S., Helgerson, S. D., McGee, H. B., Wells, J. G., Davis, B. R., et al. (1983). Hemorrhagic colitis associated with a rare Escherichia coli serotype. N. Engl. J. Med. 308, 681-685. doi: 10.1056/NEJM198303243081203

Rivas, A., Pina-Pérez, M. C., Rodriguez-Vargas, S., Zu-iga, M., Martinez, A., and Rodrigo, D. (2013). Sublethally damaged cells of Escherichia coli by pulsed electric fields: the chance of transformation and proteomic assays. Food Res. Int. 54, 1120-1127. doi: 10.1016/j.foodres.2013.01.014

Ross, W., Thompson, J. F., Newlands, J. T., and Gourse, R. L. (1990). E. coli Fis protein activates ribosomal RNA transcription in vitro and in vivo. EMBO J. 9, 3733-3742.

Sauer, U., and Eikmanns, B. J. (2005). The PEP-pyruvate-oxaloacetate node as the switch point for carbon flux distribution in bacteria. FEMS Microbiol. Rev. 29, 765-794. doi: 10.1016/j.femsre.2004.11.002

Schultz, J. E., and Matin, A. (1991). Molecular and functional characterization of a carbon starvation gene of Escherichia coli. J. Mol. Biol. 218, 129-140. doi: 10.1016/0022-2836(91)90879-B

Schwartz, C. J., Giel, J. L., Patschkowski, T., Luther, C., Ruzicka, F. J., Beinert, H., et al. (2001). IscR, an Fe-S cluster-containing transcription factor, represses expression of Escherichia coli genes encoding Fe-S cluster assembly proteins. Proc. Natl. Acad. Sci. U.S.A. 98, 14895-14900. doi: 10.1073/pnas.251550898

Sin, I. L., and Finch, L. R. (1972). Adenine phosphoribosyltransferase in Mycoplasma mycoides and Escherichia coli. J. Bacteriol. 112, 439-444.

Soisson, S. M., MacDougall-Shackleton, B., Schleif, R., and Wolberger, C. (1997). Structural basis for ligand-regulated oligomerization of AraC. Science 276, 421-425. doi: 10.1126/science.276.5311.421

Sokołowska, B., Skapska, S., Niezgoda, J., Rutkowska, M., Dekowska, A., and Rzoska, S. J. (2014). Inactivation and sublethal injury of Escherichia coli and Listeria innocua by high hydrostatic pressure in model suspensions and beetroot juice. High Pressure Res. 34, 147-155. doi: 10.1080/08957959.2013.877458
Stragier, P., and Patte, J. C. (1983). Regulation of diaminopimelate decarboxylase synthesis in Escherichia coli: III. Nucleotide sequence and regulation of the lysR gene. J. Mol. Biol. 168, 333-350. doi: 10.1016/S0022-2836(83)80 022-9

Sukharev, S. I., Blount, P., Martinac, B., Blattner, F. R., and Kung, C. (1994). A large-conductance mechanosensitive channel in E. coli encoded by $\mathrm{mscL}$ alone. Nature 368, 265-268. doi: 10.1038/368265a0

Torrents, E., Grinberg, I., Gorovitz-Harris, B., Lundström, H., Borovok, I., Aharonowitz, Y., et al. (2007). NrdR controls differential expression of the Escherichia coli ribonucleotide reductase genes. J. Bacteriol. 189, 5012-5021. doi: 10.1128/JB.00440-07

Ueta, M., Ohniwa, R. L., Yoshida, H., Maki, Y., Wada, C., and Wada, A. (2008). Role of HPF (hibernation promoting factor) in translational activity in Escherichia coli. J. Biochem. 143, 425-433. doi: 10.1093/jb/mvm243

Ulmer, H. M., Herberhold, H., Fahsel, S., Gänzle, M. G., Winter, R., and Vogel, R. F. (2002). Effects of pressure-induced membrane phase transitions on inactivation of HorA, an ATP-dependent multidrug resistance transporter, in Lactobacillus plantarum. Appl. Environ. Microbiol. 68, 1088-1095. doi: 10.1128/AEM.68.3.1088-1095.2002

Wang, J., Cheng, Y., Wu, R., Jiang, D., Bai, B., Tan, D., et al. (2016). Antibacterial activity of juglone against Staphylococcus aureus: from apparent to proteomic. Int. J. Mol. Sci. 17, 965. doi: 10.3390/ijms17060965

Wang, M. S., Zeng, X. A., Sun, D. W., and Han, Z. (2015). Quantitative analysis of sublethally injured Saccharomyces cerevisiae cells induced by pulsed electric fields. LWT Food Sci. Technol. 60, 672-677. doi: 10.1016/j.lwt.2014. 09.028

Wold, S., Crooke, E., and Skarstad, K. (1996). The Escherichia coli Fis protein prevents initiation of DNA replication from oriC in vitro. Nucleic Acids Res. 24, 3527-3532. doi: 10.1093/nar/24.18.3527

Wu, C., Zhang, J., Chen, W., Wang, M., Du, G., and Chen, J. (2012). A combined physiological and proteomic approach to reveal lactic-acid-induced alterations in Lactobacillus casei Zhang and its mutant with enhanced lactic acid tolerance. Appl. Microbiol. Biotechnol. 93, 707-722. doi: 10.1007/s00253-0113757-6

Yang, J., He, Y., Jiang, J., Chen, W., Gao, Q., Pan, L., et al. (2016). Comparative proteomic analysis by iTRAQ-2DLC-MS/MS provides insight into the key proteins involved in Cronobacter sp. biofilm formation. Food Control 63, 93-100. doi: 10.1016/j.foodcont.2015.11.029

Yuk, H. G., and Geveke, D. J. (2011). Nonthermal inactivation and sublethal injury of Lactobacillus plantarum in apple cider by a pilot plant scale continuous supercritical carbon dioxide system. Food Microbiol. 28, 377-383. doi: 10.1016/j.fm.2010.09.010

Zhao, F., Wang, Y., An, H., Hao, Y., Hu, X., and Liao, X. (2016). New insights into the formation of viable but nonculturable Escherichia coli O157: H7 induced by high-pressure CO2. Mbio7:e00961-16. doi: 10.1128/mBio.00 961-16

Zhao, W., Yang, R., Gu, Y. J., Tang, Y., and Li, C. (2014a). Assessment of pulsed electric fields induced cellular damage in Saccharomyces cerevisiae: change in performance of mitochondria and cellular enzymes. LWT Food Sci. Technol. 58, 55-62. doi: 10.1016/j.lwt.2014.03.009

Zhao, W., Yang, R., Gu, Y., and Li, C. (2014b). Effects of pulsed electric fields on cytomembrane lipids and intracellular nucleic acids of Saccharomyces cerevisiae. Food Control 39, 204-213. doi: 10.1016/j.foodcont.2013.11.015

Conflict of Interest Statement: The authors declare that the research was conducted in the absence of any commercial or financial relationships that could be construed as a potential conflict of interest.

Copyright (C) 2017 Bi, Wang, Hu and Liao. This is an open-access article distributed under the terms of the Creative Commons Attribution License (CC BY). The use, distribution or reproduction in other forums is permitted, provided the original author(s) or licensor are credited and that the original publication in this journal is cited, in accordance with accepted academic practice. No use, distribution or reproduction is permitted which does not comply with these terms. 